\title{
A Generalized Methodology for Library Systems Analysis
}

T

HIS ARTICLE IS DIRECTED toward the novice in systems work. Its purpose is to generalize at a very elementary level a methodology or approach which can be used in conducting a systems study. Systems work is discussed here as a point of view; a logical, coherent, from the top down, preface to decision-making and resource allocation which utilizes a very powerful body of sophisticated techniques. The approach and techniques reviewed in this paper, however, will be those on the most elementary level. No attempt will be made to discuss the techniques of queueing, inventory management, linear programming, simulation, marginal analysis, game theory, statistical inference, or any of the other highly sophisticated techniques available to the operations research/systems analysis (OR/SA) analyst. When the systems approach is clearly understood and properly used, it becomes a potent weapon in the arsenal of the administrator. Rather than a review of the tools themselves, a delineation of this systems methodology and point of view will be considered in this article. The methodology discussed here embraces a number of standard techniques used by the systems engineer, time and motion analyst, operations researcher, and occasionally, even the li-

Mr. Burns is librarian for research and development at Colorado State University, Fort Collins, Colorado. brarian. Examples of these techniques are scattered through the professional literature of librarianship/information science, management, industrial engineering, and operations research/systems analysis. Some of the more important references describing $\mathrm{OR} / \mathrm{SA}$ in the library have been included in the bibliography which accompanies this article. Unfortunately, many of the most basic concepts of these twin fields remain poorly understood and as a result are seldom applied by the library profession. Two glossaries of terms have been added to the bibliography for the benefit of the user who wishes additional help in understanding the terminology of OR/SA.

In the past six to eight years, only a few publications of merit have appeared in the literature showing how and under what conditions a systems study can be conducted in , a library environment. Some of these were prepared by librarians, but many of the best have been written in a highly technical jargon by individuals whose credentials are in fields other than library science. Indeed, one of the most significant developments has been the number of articles written about the library/information science field by individuals whose backgrounds are in other disciplines but who, nevertheless, have successfully used the library as a laboratory, and in doing so have given the library profession some of its most substantial contributions. 
A true systems study should be able to document for the administrative officer the goals of the administrative unit being studied and the resources available to the unit, as well as suggest alternative methods for achieving these goals within a given set of constraints. All of this must be accomplished in such a fashion that the administrator is permitted to select the proper alternatives by manipulating resources to reach his preselected goals. Fundamentally, this is a process of balancing goals with resources based on the facts gathered by the analyst. Facts needed by the administrator include such items as unit costs, unit times, costs of materials and equipment, opportunity costs, configuration and availability of equipment, movement of staff and material, and staffing patterns. It is the job of the analyst/designer to ferret out these facts and present them to the administrator with a full display of available options.

A systems study must examine both the economic efficiency of the unit being studied as well as its operational efficiency, always being careful to study each in vivo. Economic efficiency can be judged in either of two ways: the ability of the system to produce or process the same number of units for less cost; or the ability to produce more units for the same cost. The savings achieved by library automation seem largely to accrue from the second advantage. Operational efficiency is a much more subtle concept and, indeed, involves many of the intangible values with which all librarians doing systems work are constantly confronted. One measure of operational efficiency derives from user satisfaction and can be determined by the questionnaire/interview method.

The achievement of maximum efficiency within a system is an extremely subtle process requiring the fine tuning and sensitive ear which one expects of a skilled violinist. It is in no sense of the word the obvious undertaking that some managers believe it to be. An efficient system is one which has reached a correct balance between the resources and the system's achievement of its goals, or performance. However, there is a distinction between efficiency and the measures of efficiency. It is quite common for the novice in systems work to confuse the ways of measuring efficiency within a subsystem such as decreased costs, increased production, etc., with the efficiency goals of the total system. True efficiency can only be discussed validly in the context of a total system's operation.

\section{What Is a System?}

In discussing systems work, the first problem is to develop an unambiguous definition for the word system. Although it is used often and widely, the implications of this concept are seldom fully understood. As Nadler points out, there are almost as many definitions as there are people writing about the field. ${ }^{1}$ The Random House dictionary stresses the concept of a system as "an assemblage or combination of things or parts forming a complex or unitary whole. . . " The U.S. General Accounting Office, in its systems glossary, expands this to point out that "systems analysis may be viewed as the search for and evaluation of alternatives which are relevant to defined objectives, based on judgment and, wherever possible, on quantitative methods, with the objective of presenting such evaluations to decision makers for their consideration. . . ."2 Bellomy refers to a system as "an assemblage of interdependent things and ideas necessary to achieve a set of related objectives . . . characterized by inputs which are processed to produce the outputs required to achieve specified objectives. . ." "3 After examining these definitions, several ideas begin to emerge which are common to any systems effort, no matter what it may be 
called. The ideas of interrelated parts bound into a coherent whole possessing a common goal or objective are central to the systems concept. It is on these basic attributes that we shall build our methodology for a systems study.

In this article attention will be focused on the four steps or phases of a systems study which we shall call the systems survey, the systems analysis phase, the systems design phase, and the implementation/evaluation phase. This somewhat arbitrary division should not be taken to infer that these are discrete operations with a systems design proceeding only when the systems analysis effort has been completed. This would be a highly idealized solution since in actual practice the pressures to get on with the job will usually force the telescoping of these efforts. When this is done with care and in a recursive fashion, the chances of success are usually good. Each of these phases should be viewed as complementary to the others and, although they are similar and related, each must be performed in a sequential and discrete fashion, preferably in tan$\mathrm{dem}$. Some overlap is permitted, but the analysis phase always begins before the design phase, and the design phase always begins before the implementation phase.

\section{General Characteristics of a SYSTEMS EFFoRT}

Before discussing each phase in detail, several generalizations should be made about the entire systems effort. These will help the reader develop an understanding of the type of problem to which we are addressing ourselves; they are as follows:

(1) Attention to detail lies at the very heart of the systems effort and thorough precise work demands an intense preoccupation with every detail, no matter how small. Indeed, the entire systems effort hangs on the ability of the analyst/designer to unearth and ar- ticulate all the minutiae of a procedure. It would be difficult to overemphasize the importance of this aspect of systems work, for the most minute detail can jeopardize the success of an entire operation. This becomes even more critical when the systems effort involves machine planning, for machines, unlike people, will not tolerate ambiguity. This will suggest to the perceptive reader that it is wise, indeed essential, to plan several alternatives for each proposal, since the smallest miscalculation could force the scrapping of an entire proposal and change the direction of all work done up to that point.

(2) Every system is a subsystem of some larger system and each system is itself composed of a number of component subsystems. Therefore, all systems exist in both a micro and macro hierarchy depending on the perspective of the analyst. Knowing this, the analyst must constantly guard against suboptimization, i.e., the design of a component subsystem such that it operates in an optimum fashion to the detriment of the system as a whole.

(3) Systems work is a much more subtle process than simply fact gathering. It involves a thorough understanding not only of who, what, when, where, why, and how, but of the relationships which exist between the system under review and all of the other systems with which it interfaces, as well as the component subsystems which make up the system being studied.

(4) There is no single definitive measure for the effectiveness of a systemonly circumstantial optimums, each of which must be weighed against all other possible options available to the manager.

(5) Systems are generally designed for the normal operation (quantitatively, the mean or median), and only rarely will the goals of the system permit design for the exceptional conditions.

(6) All systems work is by nature re- 
cursive with each successive repetition performed either at the same or at a different level.

(7) Continuous feedback and monitoring are essential components of the systems effort. ${ }^{4}$ One of the major difficulties in optimizing present manual library systems has been the lack of adequate provision for valid feedback.

(8) By definition, all systems must exist within an environment. The environmental factors are those which affect or relate to the system under discussion but which are not a part of that system. The analyst cannot fully describe the system without also delineating its environment.

(9) There is a danger in any systems work that it will attempt to quantify that which cannot be quantified-the intangible factors. Overquantification can become a very serious problem and often leads to a credibility gap in the entire systems effort.

(10) Documentation is as much an essential part of the systems effort as analysis, and to ignore or discount this aspect of systems work is to invite disaster.

(11) There is never any final phase to a systems effort, only iteration.

Library systems work provides us with excellent illustrations for each of the above axioms. For example, the failure to write down and describe all the steps in a systems effort as they take place, has forced many SA projects to start again whenever a change of personnel takes place. Or, how many librarians have unknowingly insisted upon a system which will handle all exception routines and then wondered why the system took so long to develop or refused even to work at all? Library systems are difficult to analyze, not because of their size, but because they are often unstructured, lack adequate provision for feedback and monitoring, and are always so interrelated and interdependent that the best descriptions of them are of dynam- ic systems which have "evolved" over a long period of time through a trial and error process. Developing models for this type of a system, especially mathematical models, is a particularly difficult undertaking and can lead to very misleading conclusions unless the model builder understands the proclivity of mathematical modeling for oversimplification.

In fact, most of the dilemmas which plague all systems work also exist in the library systems effort. As with any systems work of magnitude, the analyst finds himself on the horns of a dilemma at the very beginning of his study. Machol has pointed out that the problems of designing a large system are often of such magnitude as to make the problem indigestible and even unsolvable if attacked all at once. ${ }^{5}$ Yet the analyst cannot arbitrarily divide the problem to study it piecemeal without running the risk of losing the continuity of the whole. Where then does a realistic approach exist between these two extremes? A partial answer lies in the perspective of the analyst, in his ability to maintain a continuing balance between the unity of the whole and the detail of the part.

\section{Steps in the Systems Study}

The systems effort begins with a problem defined by the analyst as a system existing in an environment of other systems and bound by certain constraints. The first step is to isolate the system under review so that it can be described in an unambiguous fashion. This is the systems survey stage and marks the beginning of a series of successive partitionings which take place until the system has been divided into the smallest logical component still capable of being identified with the system being studied. This process of system dissection is analogous to the molecular theory of chemistry which defines 
a molecule as the smallest particle of matter still exhibiting all the characteristics of the larger mass (system) from which it came. After dividing the system into its molecular components, the analyst then proceeds to delineate the alternatives he has created by rearranging these component parts in whatever fashion the resources and goals of the system will allow, always being careful to work within the constraints which the system's environment dictates. The analyst then proceeds to evaluate these alternative solutions in the light of the stated goals or objectives and selects from them a preferred course of action which he recommends to the decisionmaker. Thus, evaluation/implementation becomes the last sequential step of the systems effort and is followed by whatever iterations are deemed necessary by the decision-maker to reach the goals of his agency.

\section{SYSTEMS WORK FROM THE Administrator's ViewPOINT}

At this point it might be appropriate to shift perspective and discuss systems work from the administrator's point of view; that is, in terms of the agency's goals, choices, resources, and inputs/outputs. Each administrator has at his disposal four categories of resources: staff, space, funds, and time. (To this some would add a fifth resource-information.) The mix a manager adopts to meet the goals of his administrative unit has depended in large measure upon his own judgment which up to now has been, at least in part, intuitive. In the course of getting the job done or reaching a goal these resources will of necessity be consumed to a greater or lesser degree. It is the responsibility of the manager to balance continuously the availability and consumption of these resources with his goals in order to assure that the goals are reached in the most efficient fashion possible.
Furthermore, a large portion of systems work consists of no more than asking questions about all those assumptions and operating norms which up to now have been accepted as obvious, axiomatic, or based on historical prerogative, and in so doing to pare away the obfuscation which tends to grow up around a deep-seated procedure.

But how does all this apply in a library environment where the goal is that nebulous entity "service"? In order to answer this question realistically, one must first decide what constitutes the library's service goal. The author has chosen to adopt the definition of the library's goal that Mackenzie has used: "to assist in the identification, provision and use of the document or piece of information which would best help the user in his study, teaching or research, at the optimal combination of cost and elapsed time. ..."6 Efficiency, when used in this context, becomes either answering more of the "needs" of a reader while holding costs and elapsed time constant, or meeting the same needs while cutting down costs and elapsed time. However, neither explanation of efficiency is entirely satisfactory when used in this fashion because the process described here is one using only quantification as the valid criterion for evaluating its success. This is not to imply that there are no areas in library systems analysis which can be evaluated in a quantitative sense-there most definitely are. It is merely to emphasize for the systems person that he cannot quantify all aspects of a library system. Indeed, insofar as any systems study attempts to use quantitative methods where they are not appropriate, the study will fail and, unfortunately, the reason will not always be clear to all concerned. What the analyst cannot do is quantify the intangible benefits from a course of action, and it is here that the administrator will need to depend most heavily upon his own experience and intuition 
for guidance. What follows is a generalized methodology for the systems approach to problem-solving.

\section{First Phase: The Systems Survey}

In the first phase of the systems study, the analyst conducts what is called the systems survey, during which he relates the system under review to other systems in which it is embedded-to its environment if you will-by determining what is germane to the problem being studied. Once these boundaries have been established, the analyst begins to lay out the problem in very general terms, specifying the goals and functions of the system under review. This involves familiarization and departmental orientation of the analyst, preparation of such tools as a list of the files maintained, their contents, and the organization of each; a list of the forms being used with examples of each; and a description of their movement, and associated activities; a review of all procedural manuals and job descriptions; and finally a documented statement of the system's goals. ${ }^{7}$ When used in this context, a goal can be thought of as either a direction or an objective or a combination of both. It can be a point to be reached or a line of march to be followed in moving toward this point. But each goal must also be defined in terms of the expected performance of the system. In fact, any discussion of goals which does not include a statement of the performance expected from the system is so innocuous as to be irrelevant and makes the entire discussion meaningless. Statements of performance coupled with goals have the added advantage of helping to prevent a dichotomy from developing between the real and stated goals.

\section{Second Phase: Analyzing THE SYSTEM}

The analyst is now ready to begin the second phase of his study, preparation of a block diagram or system schematic, which outlines in a very general way the tasks performed by the system and the relationships which exist between the subsystems. ${ }^{8}$ This is the first level of definition and is, of necessity, very gross. For a library circulation system these boxes might be charging, discharging, searching, shelving, etc. Each box is then further subdivided into its appropriate tasks down to the procedural level, showing the movement of people and materials through all subsystems. This is accomplished by using flow process charts first and then by using flow decision charts.

Construction of the block diagram and the flow charts are the first concrete expressions of an analysis effort which up to now has been primarily a data gathering and intellectual exercise. Flow process charts enable the user to visualize at once the movement of a person and, for example, the distances traveled in checking out a book. The chart will also point out for the user how many times a book is "inspected" as it moves through a given routine. The flow decision chart, on the other hand, uses a different set of symbols and shows at what points decisions are made and how these decisions affect the flow of materials/ people. In his charting, the analyst works at a very specific level where he is concerned with discrete entities capable of quantification in terms of how long, how many, how much, and how often. Indeed, his next task is to begin the quantification of these steps by carefully tabulating the number of times a given symbol was used on the flow process chart and the time necessary to move through these steps. Parallel with this effort, the analyst should be identifying activities and compiling these into a document known as a standardized activities list. It is also customary to document the levels of personnel performing these tasks. 
Thus far, the analyst has dissected the system-in this case, a library loan desk-through the activities (charging, discharging, etc.) and procedures (how a card is returned to a book in the discharging activity) levels with all the components enunciated at each level. As he does this he also begins the timing of these component subsystems at the procedural or task level. At the same time, the analyst should begin the process of deriving costs by determining what are the real wages (direct + indirect/productive time on job) paid to staff in order that he may translate unit times into unit costs. When this exercise has been finished, the analyst can measure quantitatively the available alternatives, at least in terms of costs, and offer these to the decision-maker for review.

There still remains the difficult problem of evaluating intangibles-those factors which cannot be quantified, such as convenience, availability, prestige, etc--and if the cost studies have been close, intangibles become crucial to the decision-making process. Intangibles will add support to a program only when definable costs can actually be used to demonstrate a more efficient operation. In other words, the intangible factors can only be used to buttress an argument and never as the sole reason for modification of a system, experience and intuition aside. The point is that more subtle techniques of quantification must be used before funds can be invested in any change which intuitively appears to yield better results.

\section{Third Phase: Design of THE SYSTEM}

The next phase, systems design, usually follows when the analysis efforts have been completed and carefully digested. In theory, these steps should be discrete. In actual practice, however, they seldom are, for the design efforts will often overlay the analysis studies. Usually design consists of a modification of the existing system-a rearrangement of the components in the old system-but with possible additions or deletions modifying any or all inputs of the resources discussed earlier, and always within the context of the systems goals.

\section{Fourth Phase: Implementation and Evaluation of THE New SySTEM}

The final phase begins with the implementation of the prototype system and its test/evaluation. This is often the most expensive single phase and its success depends on all earlier phases being in a state of completion. Up to this point the entire process has been a recursive one of dividing, measuring, charting relationships, defining, then repeating the whole process of quantifying the characteristics of the component systems, charting relationships again, and repeating the cycle. Because of economic constraints, however, the implementation and prototype phase cannot always be repeated easily. Therefore, it behooves the analyst to work with meticulous care once this phase of the systems effort has been entered. Another point which should be brought to the reader's attention here is that firsttime processing costs, procedures, etc., are normally atypical and cannot be judged to remain constant throughout the life of a system. These are not the nonrecurring costs normally associated with the activation of a system, but those unit costs and unit times which would normally be expected to remain constant throughout the life of the system. The first complete operating cycle is never typical, no matter how carefully the planning and design work was done. There is always the problem of the unforeseen, and no analyst, no matter how good, is ever able to plan for all contingencies. 


\section{Conclusion}

Hopefully, the reader now has a better understanding of the intricacies and nuances inherent in systems work. It is obvious that such work is a prerequisite to library automation, but it does not necessarily follow that automation will automatically succeed the systems efforts. Indeed, the study can easily indicate that library automation is not appropriate given the existing resources of time, money, staff, or space. In essence then, systems work is a method-part science, part art-whereby one determines the correct balance between constraints and the resources necessary to realize predetermined goals, and leads to the establishment of realistic priorities based upon a thorough understanding of the total system being studied and its relationship to all other systems having a common interface.

\section{REFERENCES}

1. Gerald Nadler, Work Design (Homewood, Ill.: Richard D. Irwin, 1963), p.87ff.

2. U.S. General Accounting Office, PlanningProgramming-Budgeting and Systems Analysis Glossary (Washington: U.S. G.A.O., 1968) p.40.

3. Fred L. Bellomy, "Management Planning for Library Systems Development," Journal of Library Automation 2:187-217 (Dec. 1969).

4. "Feedback," The Systemation Letter 166: 4p. (1965).

5. Robert E. Machol, ed., System Engineering Handbook (New York: McGraw-Hill, 1965), p.1-5.

6. A. Graham Mackenzie, "Systems Analysis of a University Library," Program 2:7-14 (April 1968).

7. Ibid.

8. Robert Hayes, "Library Systems Analysis," in Data Processing in Public and University Libraries, ed. by John Harvey (Washington: Spartan Books, 1966), p.5-20; and C. D. Gull, "Logical Flow Charts and Other New Techniques for the Administration of Libraries and Information Centers," Library Resources \& Technical Services 12:47-66 (Winter 1968).
BIBLIOGRAPHY

\section{Basic and Introductory Material of Special Value to Librarians}

1. Herner, Saul. "Systems Design, Evaluation, and Costing," Special Libraries 58:576-81 (Oct. 1967).

2. Bellomy, Fred L. "Management Planning for Library Systems Development," Journal of Library Automation 2:187-217 (Dec. 1969).

3. Dougherty, Richard M., and Heinritz, Fred J. Scientific Management of Library Operations. New York: The Scarecrow Press, 1966. 258p.

4. Hayes, Robert. "Library Systems Analysis," in John Harvey, ed., Data Processing in Public and University Libraries, p.5-20. Washington: Spartan Books, 1966.

5. Becker, Joseph. "System Analysis-Prelude to Library Data Processing," ALA Bulletin 59:293-96 (April 1965).

6. Leimkuhler, Ferdinand F. Mathematical Models for Library Systems Analysis. School of Industrial Engineering, Purdue University, Sept. 1967. PB 176113.

7. MacKenzie, A. Graham. "Systems Analysis of a University Library," Program 2:7-14 (April 1968).

8. Burkhalter, Barton R. Case Studies in Systems Analysis in a University Library. Metuchen: The Scarecrow Press, 1968. 186p.

9. MacKenzie. ibid.

10. Kilgour, Frederick G. "Systems Concepts and Libraries," CRL 28:167-70 (May 1967).

\section{Advanced Texts}

11. Morse, Philip M. Library Effectiveness: A Systems Approach. Cambridge: The M.I.T. Press, 1968. 207p.

12. Raffel, J. A., and Shishko, Robert. Systematic Analysis of University Libraries: An Application of Cost-Benefit Analysis to the M.I.T. Libraries. Cambridge: The M.I.T. Press, 1969. 107p.

13. Machol, Robert E., ed. System Engineering Handbook. New York: McGraw-Hill, 1965. p.1-5.

14. Nadler, Gerald. Work Design. Homewood, Ill.: Richard D. Irwin, 1963. p.87ff.

\section{Specialized Articles Covering Techniques}

15. Poage, Scott T. "Work Sampling in Library Administration," Library Quarterly 30:21318 (July 1969).

16. Fazar, Willard. "Program Planning and 
Budgeting Theory," Special Libraries 60: 423-33 (Sept. 1969).

17. Kozumplik, William A. "Time and Motion Study of Library Operations," Special Libraries 58:585-88 (Oct. 1967).

18. Gull, C. D. "Logical Flow Charts and Other New Techniques for the Administration of Libraries and Information Centers," $L i$ brary Resources \& Technical Services 12: 47-66 (Winter 1968).

19. Aslib Research Department. "The Analysis of Library Processes," Journal of Documentation 26:30-45 (March 1970).

\section{General Material}

20. U.S. General Accounting Office. Planning -Programming-Budgeting and Systems Analysis Glossary. Washington: U.S. G.A.O. , 1968). p.40.

21. Spencer, Donald D. The Computer Pro- grammer's Dictionary and Handbook. Waltham, Mass.: Blaisdell, 1968. p.41.

22. Rivett, Patrick. An Introduction to Operations Research. New York: Basic Books, 1968. 206p.

23. Churchman, C. West. The Systems Approach. New York: The Delacorte Press, 1968. 243p.

24. "Feedback," The Systemation Letter 166: 4p. (1965).

25. "Analysis . . . The Second Essential Step," Systemation: A Semi-Monthly Letter on System Trends and Techniques 12:4p. (1 Oct. 1958).

26. Heyel, Carl, ed. The Encyclopedia of Management. New York: Reinhold Publishing Co., 1963. p.613. Taken from Pocock, John W. "Operations Research; Challenge to Management," Special Report no. 13. New York: American Management Association, 1956. 